\title{
NOTAS DE BIBLIOGRAFIA E DE CRÍTICA
}

\author{
J O R G E D E L I M A
}

Dificilmente haverá morte mais sentida e carpida que a do poeta de "Essa negra Fulô", ocorrida no mês de novembro ültimo. Ficou na sombra o poeta, o romancista, o ensaista, o pintor que nele havia e que indicavam o seu polimorfismo e a variedade de seus instrumentos de expressão para avultar e crescer aos nossos olhos o homem bom que êle fôra, amigo de toda gente, sempre pronto e solicito em atender a quem o procurasse em seu consultório de médico. Um consultório que excedia de seus limites, mais um ponto de encontro de intelectuais e amigos, para quem o poeta sempre tinha uma palavra especial de simpatia e conforto, quando era o caso. Não resta dúvida que êle soube fazer amigos e admiradores, dada essa capacidade de comunicação e receptividade que nele parecia obedecer a um impulso natural, não atentando para qualquer incompatibilidade de idéias ou de crença. Católico, nem porisso Jorge de Lima deixava de acolher bem quem não rezasse pela sua cartilha. Não só isso, mas também distribuindo à larga os seus cuidados médicos, sem nenhuma preocupação de ganho, principalmente quando se tratava de intelectuais. $O$ homem bom que havia nele justificava a atitude que os maldizentes lhe atribuiam de estar assim preparando a sua glória, tudo fazendo em favor de sua publicidade, para a qual reservou sempre atençōes muito carinhosas. Näo há, no entanto, como recriminé-lo por isso, uma vez que todo homem de letras timbra em cultivar a sua vaidade, tantas vêzes legitima. As suas tentativas de ingressar na Academia são um exemplo bem expressivo.

Talvez seja ainda cedo para se fazer em termos mais ou menos equilibrados o levantamento da obra tāo rica em sugestōes e indicaçōes de Jorge de Lima. A sua inquietação, os vários caminhos por que andou trilhando, são sem dúvidas obstáculos a vencer. $€$ provável que o poeta venha a dominar. Mas ainda assim, em torno de sua produção mais discutida, ou melhor, mais falada, Invenção de Orfeu, em que concentrou o seu maior labor, há muito que respigar, se bem que seja indiscutivel a riqueza e a plasticidade expressionais do poema ao qual, porém, a feiçāo épica, intencional e deliberada, nāo deixa de acrescentar qualquer coisa de superfetaçāo ou de artifício comprometedor.

De qualquer modo, o poeta sobrevivera. Talvez mais o poeta folclórico dos Poemas Negros, dessa peça ainda bastante vivaz que é "Essa Negra Fulô", a despeito de escrita há mais de vinte anos.

$$
\text { T. } \mathbf{L} \text {. }
$$

LAMPI.aO, drama em cinco quadros, de Rachel de Queiroz, ed. José Olympio, 1953.

As qualidades plésticas da prosa de Rachel de Queiroz, a .sua espontaneidade, a naturalidade e a frescura de seus diálogos estão neste drama a serviço de um tema senāo ingrato, pelo menos incompatível como o cangaço, que é ou foi uma atitude mais restrita à taciturnidade e, portanto, 
avessa à ação teatralizável, no sentido de se poder tirar partido da linguagem oral. Assim, os tipos de cangaceiros que entram em cena estão Ionge de conferir com a realidade. Como admitir um Lampiāo loquaz? Eis de certo a maior incongruência desta peça que nos oferece um retrato idealizado e por demais fantástico do bandido das caatingas nordestinas. Tão fantástico que ele chega até a se transformar em homem bom, investido de sensibilidade, incapaz de cometer injustiças, passando os seus perseguidores, sim, a ser os verdadeiros crueis, os fora da lei. Não deixa de haver, assim, uma certa frustração nesses excessos de idealização. Seria o mesmo que querer ver em Hitler, nāo a maior encarnaçāo do espírito belicoso, o provocador da maior guerra de todos os tempos, mas a amigo da paz e da humanidade.

T. $\mathbf{L}$.

A ILHA E OUTRos Contos, de AImeida Fischer, ed. "Os Cadernos de Cultura", Ministério da Educação e Cultura, 1953

Volta o autor, neste pequeno volume, a um gênero - o conto - para - qual já havia demonstrado em tentativa anterior apreciáveis recursos. Almeida Fischer é um dos nossos bons e raros contistas, não obstante ele não se afirme como um renovador desse difícil tipo de ficção. Um renovador da força de um Dalton Trevisan ou de um Murilo Rubião, por exemplo. A despeito disso, muitos segredos de vida sāo captados aqui. O autor sabe explorá-lo bem e revela dotes capazes de o fazer transcender os quadros convencionais do conto brasileiro. Se bem que o primeiro conto seja o que mais nos agrada nesta coletânea, os outros se mantêm mais ou menos no mesmo nivel, em favor de uma homogeneidade que representa e indica o grau de amadurecimento já atingido pelo escritor.

T. $\mathbf{L}$.

\section{PÁtro, contos, de Saldanha Coelho, ed. Revista Branca}

Cremos ser o sr. Saldanha Coelho participe da opiniāo que vê no conto uma forma de arte moderna, uma arte de silencio, um instantâneo colhido num segundo, ao contrário do romance, que seria no caso uma longa "pose". Uma forma, afinal, de ficção que exige mais do leitor, em compensação, cabendo-lhe exercitar a imaginação e, portanto, a sua participação também. E o que deixam entrever estes contos, os quais, porém, divergem em valor e substância. O gosto do insólito continua a ser, contudo, uma de suas notas mais características. De qualquer modo, o conjunto deixa uma impressão de diversidade, de um mundo pessoal, bastante dispar, para poder despertar um interesse igual. A nosso ver, o melhor conto do livro é o segundo, intitulado "Raquel". Em seguida vem "Giasone", o primeiro. Os outros, conquanto revelem uma perfeição formal apreciavel, uma técnica despojada de artificios, já não nos parecem ficar no mesmo nivel desses dois.

T. $\mathbf{L}$.

SOL SEM TEMPo, de Péricles Eugênio da Silva Ramos, ed. Clube de Poesia de Sáo Paulo, 1953

Eis um poeta, pertencente à chamada geração de 45 , que se mostra bem diferente dos que formam o modernismo nasciao em 22. Com ele, certamente, não seria difícil estabelecer uma solução de continuidade entre os novos e o modernismo. A sua atitude poética se caracteriza sobretudo pela riqueza da fórma, pela dominação completa do instrumento poé- 
tico. Naturalmente que o autor vê af a maior fonte do essencial poético, sem se preocupar absolutamente com uma poesia de função social, como reflexo do mundo. E claro que nāo se fala em nenhum especialista em poesia. Ou numa poesia conduzida por estandartes ou bandeiras. Dessa sua atitude, evidentemente, é que decorre o hermetismo deste livra de poemas, que não deixa de constituir sério impecilho para a comunicação ao leitor. Ao leitor inteligente, uma vez que o leitor comum se sente desde logo incompetente para a leitura. E inegável que se trata de alguem dotado de profundos contactos com a história da poesia, que a estuda e a acompanha seriamente, como muito poucos entre nós. Não resta dúvida que o livro contem belas soluções formais, imagens felizẹs, um tom às vezes valeryano. Mas, ainda assim, por mais receptivo que se tenha o espírito, estes poemas oferecem alguma resistência de comunicaçāo. Não chegarão a nós pela via do encantamento, mas somente aos esforços bastante ponderáveis, em que entre um coeficiente de respeito e admiração pela cultura poética de seu autor.

T. $\mathbf{L}$.

\section{O Hóspede e a ILHA, de Colombo de Sousa, ed. Escola Técnica de Curitiba, 1953.}

O maior mérito deste poeta está no seu anseio de renovação, vindo como ele veio do soneto parnasiano, que chegou a fazer bem. Hoje o que se sente em seus versos é ainda uma impressão caótica e confusa, conquanto não se achem despidos de algumas qualidades Qualidades mals perceptiveis na ordem formal e que nāo são de molde a justificar plenamente a transformaçāo sofrida pelo poeta, principalmente na parte relativa à própria concepção fundamental de poesia. Esta passou a se acentuar apenas por um jogo de palavras, em que a escolha da imagem ou da metáfora ainda deixa muito a desejar. Se poesia se faz com palavras, isso não quer dizer pura e simplesmente que basta reuni-las numa cadência ou num ritmo, sem nenhuma preocupaçāo de se comunicar pelo raciocinio ou pela sensibilidade. Estes versos nos dāo acaso a sensação de alguma coisa? Da angustia, da inquietude ou mesmo do esforço penoso do poeta para nos trazer ao conhecimento alguma coisa de real e de profundo? Torna-se dificil responder.

T. L.

JORNAL DE FILOLOGIA, vol. I, n. 1 (julho a setembro de 1953); n. 2 (outubro a dezembro de 1953).

o prof. Silveira Bueno, da Universidade de S. Paulo, é o diretor desta nova revista de filologia, que se apresenta como publicação da Faculdade de Filosofia, Ciências e Letras daquela Universidade. O corpo de colaboradores até agora escolhidos inclui vários dos melhores filólogos brasileiros, o que, por certo, assegura à revista a boa qualidade que é de desejar numa publicação cientifica de linguiistica. Assinalamos entre os colaboradores dois professôres da Universidade do Paraná, Mansur Guérios (Língua Portuguêsa) e Pinheiro dos Reis (Filologia Românica). Notável é a reunião de um grupo de lingüistas que se tèm dedicado ao estudo dos diomas indígenas: Lemos Barbosa, C. Drumond, J. Philipson, Paula Martins, Mansur Guérios, Plínio Ayrosa. Esta reunião, embora de certo não preconcebida, talvez seja de ótimos auspícios, pois pcderá permitir que o Jornal de Filologia se torne campo propício ao desenvolvimento dos estudos de lingǘística americana, que tanto carecem de ser incrementados. Neste sentido, é apreciável também a presença, entre os colaboradores, de dois antropólogos. especializados nos es- 
tudos do índio: H. Baldus e E. Schaden. Aliás, uma colaboraçāo da linguifstica com a antropologia, como convém, é prevista no programa dos redatores da revista, delineado na Apresentação: "A todos oferecemos as páginas de nossa revista bem como aos etnólogos, aos antropólogos, aos estudiosos da sociologia e da psicologia, naqueles problemas grandemente relacionados e entrelaçados aos da ciência da linguagem" (p. 2).

Os fins a que se dedica a nova publicação assim estão indicados: "Destina-se a revista a divulgar estudos de filologia, tomado o vocábulo em seu mais vasto sentido. Especialmente, porém, traz em mira as pesquisas feitas no terreno da língua portuguêsa do Brasil, đo seu substrato tupi-guarani, das influências de outros idiomas aqui trazidos e mantidos pelas coletividades estrangeiras bem como das línguas africanas dos tempos coloniais" (p. 1).

Além das colaboraçōes que constituem seu corpo, apresenta o Jornal de Filologia uma seção de "Filólogos brasileiros", em que em cada número é prestada homenagem a um dos estudiosos brasileiros que se destacaram no campo da filologia; uma seção de "Transcriçōes", em que se reeditam artigos aparecidos em outras publicaçōes e que a redação estima "de imediato interêsse aos estudiosos do Brasil" e destina "mais diretamente aos alunos das Faculdades de Letras" (p. 67); e seçōes de crítica de livros e revistas e de noticiário.

O número 1 traz artigos de Silveira Bùeno (Influência italiana na fala de São Paulo), Maurer Jr. (Unidade semântica da România ocidental: os empréstimos de sentido), E. Schaden (Aculturação lingüística numa comunidade rural), J. Philipsen (La enseñanza del Guaraní como problema de bilingüismo) e $\mathrm{J}$. Cretella Jr. ( $\mathrm{O}$ objeto da estilística). Na seção de filólogos brasileiros figura Otoniel Mota; na de transcriçōes é contemplada Elza Paxeco ("Arte de trovar" portuguêsa). Repara-se neste número que apenas os artigos de S. Bueno e Cretella Jr. sejam inéditos.

O segundo número apresenta colaboraçōes de Maurer Jr. (A linguística e a gramática), Silveira Bueno (Influência do Tupi no Português do Brasil), Sousa Lima (O pensamento romântico de Sílvio Romero), Cretella Jr. (O aspecto e o tempo no sistema verbal), Mansur Guérios (Alguns caracteres da evolução fonética) e E. T. Rosenthal (As cantigas do rei Henrique); o filólogo brasileiro homenageado é Oscar Nobiling; a transcrição é de Silva Ribeiro (Breves notas a uma edição brasileira do "Auto das Regateiras de Lisboa").

Aqui nos limitamos a fazer o registro do aparecimento do Jornal de Filologia, pois não há espaço para uma recensão dos artigos que o constituem, entre os quais há bastante diferença, variando êles de boas colaboraçōes com materiais e idéias de primeira mão até simples escritos de divulgação.

Fazemos votos que a nova revista se constitua um fator de progresso dos estudos lingüísticos no Brasil e que, para isso, tenha longa vida, o que bem lhe pode garantir a instituição que a publica.

\section{A. D. Rodrigues}

\section{PIERRE GROULT}

A língua portuguêsa, creio, será ainda por muito tempo a gata borralheira entre suas irmãs grãfinas da Europa. Poucos a conhecem, muitos a têm por simples dialeto espanhol. E quando alguém da importância de um Bevin promete às empregadas portuguêsas que estudará um dia a lingua delas se tiver ócios para tanto, nós nos embandeiramos em arco, puerilmente, como crianças grandes se divertem com serpentina em carnaval patriótico. 
Por mais que nossos clássicos forcejam por reconhecer nessa "última flor do Lácio" belezas incomparáveis como aquêle empedernido Francisco Rodrigues Lobo do "branda para deleitar, grave para engrandecer, eficaz para mover, doce para pronunciar, breve para resolver"; por mais que vituperem as nossas desidias em aprendê-la e em atribuir seus males aos "seus naturais que a trazem mais remendada que capa de pedinte", força é reconhecer que o prestígio de nosso idioma é muito pequeno para se impor fora dos países que o têm por língua nacional.

A ignorância do vernáculo é alarmante, fora e dentro de seu âmbito geográfico. A tecla, num e noutro caso, já está muito sovada e, por isso mesmo, excessivamente enfadonha. Não adianta regar de prantos e jeremiadas o túmulo dos clássicos, nem rasgar farisaicamente as vestes em sinal de luto. Adianta, isto sim, adquirirmos nós mesmos um conhecimento efetivo e prático dêsse poderoso instrumento de comunicação, se queremos seja êle cultuado dentro de nossas fronteiras. $E$ que uma política sábia de divulgação empenhe os homens de govêrno a levar através dêle o nosso pensamento a outras nações. Tudo isso, sem patriotices nem quixotadas.

$\mathrm{E}$ os estrangeiros que estudam português, quantos? Pouquíssimos. Uns corajosos, sem dúvida. Mas se excusamos de boa mente o "homem da multidão", não podemos usar de igual benevolência com aquêles que se pavoneiam de romanistas e que, às vézes, de fora de nossas fronteiras, nos querem dar liçōes.

Realmente temos tido sorte com os filólogos alemães que se ocuparam do português. Quem ignora a regra de Diez sôbre o emprêgo do infinito flexionado? E a famosa gramática do português arcaico de Huber? Que estudioso há por ai que desconheça as magistrais "Liçōes de fillologia portuguêsa" de Carolina Michaelis?

Infelizmente não merecem tais.gabos certos franceses e belgas. "Le français, afirmou um maldoso, est un homme mal traduit (tem fama de saber apenas a lingua própria) que ne connait pas la géographie". E acrescento eu: os súditos voluntários ou não do rei Leopoldo também.

Lembrou-me tudo isso a leitura de um manualzinho " $\mathrm{La}$ formation des langues romanes", editado em 1947, da autoria de Pierre Groult, professor de filologia românica em Lovaina. Certas afirmaçōes aí contidas estão a pedir destaque e refutação. Escolho umas poucas para não levar estas considerações muito além do espaço que lhes é reservado; ponho entre aspas as citaçōes traduzidas para nāo acrescentar ao trabalho do linotipista de ler êstes borrōes o enfado de compor em francês.

Inicialmente, numa espécie de prefácio um tanto original, ou coisa que o valha, declara o autor que todos compreenderāo êle concentre a atenção nas páginas a seguir", nas très grandes línguas literárias: o francês, o espanhol e o italiano". (pg. 26). E cumpre a promessa. Deixa sistemàticamente de lado o portuguess $e$, quando lhe sucede citar-lhe alguma coisa, comete sucessivas "gaffes" pouco recomendáveis para um professor universitário da matéria em questāo. Uma lástima!

Ao tratar da expansāo das línguas românicas e especialmente do português, insinua que êste nāo ganhou muito com o descobrimento do Brasil se bem que contemos, pela sua estatística cabulosa, quarenta milhöes de habitantes, e na sua matemática, seis vèzes mais que a antiga mãe-pátria. Sabem por quê? $E$ simples: porque contamos entre os "territórios de importância secundária" e porque, apesar daqueles dados, "ninguém imaginará que as tribos das florestas virgens falem português”, (pg. 67). Muito bem! Para o sr. Groult não passamos de quarenta milhōes de botocudos, habi- 
tantes selvagens de florestas virgens! Que tal se êle consultasse um atlas de curso primário! Não seria boa idéia enviar-lhe um exemplar?

Versando oposiçōes entre o latim clássico e o falado, faz questão de mostrar que o ESSE literário viu nascer ao seu lado um ESSERE "ao qual sòmente podem prender-se ESSERE (it.), ETRE (fr.), SER (esp.)" pg. 69. Ora, o SER castelhano, talqual o português provém de SEDERE, qualquer estudantinho de gramática histórica sabe ou suspeita isso. Será bom que êsse Ménage redivivo corrija o disparate na próxima edição para não comprometer seus abalados créditos etimológicos...

No capítulo da vocalização e reduçáo do ditongo conseqüente declara: "o português OUTRO sugere a intermediária oU (entre $O U$ e $O$ ), que aliás pronuncia igualmente $O "$ (pg. 117). Convinha acrescentar: na linguagem descuidada e em formas dialetais.

Tôda gente sabe que a etimologia dos nomes de familia, de parentesco, encerra alguma complexidade. $O$ nosso professor Groult encarregou-se de complicá-la ainda mais com inverdades, quando, p. ex., diz que "para COUSIN o português emprega o têrmo CO-IRMÃO" (sem o til, naturalmente). Será necessário explicar? (pgs. 143).

Enfim, na formação do comparativo de superioridade anota como secundário o fato de que PLUS eliminou largamente MAGIS, que só ficou na Rumânia, na Espanha (exceto Portugal) e em parte do sul da França", (pg. 182). O engano salta aos olhos. No português arcaico: é certo, tivemos CHUS, proveniente de PLUS, a par de MAIS originário de MAGIS. Mas a forma que prevaleceu foi a segunda, portanto, a ressalva entre parêntesis foi infeliz.

Como se viu, quase tôdas as vêzes que o nosso romanista (não convém dizer que é das Arábias porque é de Lovaina...) tratou de nossa língua, meteu horrivelmente os pés pelas mãos como se fôsse bisonho em assunto de sua especialidade.

Desculpe-se aos estrangeiros, sobretudo aos europeus, o não saberem a nossa língua: perdoemos-lhes não desejem ler Camóes no original, nem conheçam nossa terra e nossos costumes. A culpa é, em parte, nossa.

Mas que romanistas de universidades famosas não dêem êsse triste espetáculo de incompreensão, desleixo ou falta de cultura... Melhor fốra o silêncio como prova cabal de ignorância completa.

Oswaldo Pinheiro dos Reis 